\title{
Phenotypic and genotypic variation in Giardia lamblia isolates during chronic infection
}

\author{
P D Butcher, A M Cevallos, S Carnaby, E M Alstead, E T Swarbrick, M J G Farthing
}

\begin{abstract}
- Two Giardia isolates were axenised in vitro after recovery by duodenal aspiration from a man with hypo- $\gamma$ globulinaemia and chronic giardiasis, before and after three unsuccessful courses of metronidazole. In vitro drug sensitivity assays showed that the pretreatment isolate was sensitive to metronidazole with minimum inhibitory concentration (MIC) and dose that inhibited growth by $\mathbf{5 0 \%}\left(\mathbf{E D}_{\mathbf{5 0}}\right)$ values of 0.1 and $0.03 \mu \mathrm{mol} / 1$, respectively. The post-treatment isolate was 20 -fold more resistant (MIC and ED $_{50} 4.3$ and $0.58 \mu \mathrm{mol} / 1$, respectively). Differences between these isolates were also found in the surface protein profiles after radioiodination, metabolic labelling patterns with ${ }^{35} \mathrm{~S}$-methionine, malic enzyme isoenzyme patterns, and by DNA fingerprinting with a $\mathbf{M}-13$ bacteriophage probe. The phenotypic and genotypic differences between the pretreatment and posttreatment isolates suggest that we have isolated two different strains from the same patient and that treatment with metronidazole resulted in selection of the more resistant strain.
\end{abstract}

(Gut 1994; 35: 51-54)

Giardiasis is the most common protozoal infection of the gastrointestinal tract. It is a frequent cause of travellers' diarrhoea and may be responsible for retarded growth and development in children. The infection is usually self limiting, being cleared within six weeks in $90 \%$ of cases. Treatment with an appropriate druz results in rapid improvement of symptoms and eradication of the parasite in $94 \%-100 \%$ of cases. ${ }^{12}$ Treatment failures have been documented, however, in both immunocompetent and immunodeficient patients. ${ }^{2-8}$ The mechanisms of failure of treatment are not completely understood. Some failures are probably due to inappropriate dose or failure to comply with the treatment and others to defects in the immune system of the host. Drug resistance has been proposed as another important mechanism. Differences in metronidazole sensitivity in vitro have been reported in Giardia isolates in axenic culture. ${ }^{910}$ In a clinical study that compared in vitro sensitivity of Giardia isolates to giardiacidal drugs with the clinical response to treatment, the two Giardia isolates with the lowest sensitivity to furazolidone were from patients who had persistent symptoms after treatment with this drug. ${ }^{.1}$ Furthermore, treatment with combined chemotherapy has been successful in eradicating the parasite when single drug regimens have failed. ${ }^{2-5}$ Until now all studies considering the question of drug resistance have used only one isolate obtained either before or after treatment, thus providing limited information about the mechanisms involved in treatment failures.

We have obtained two Giardia isolates from a patient with hypo- $\gamma$ globulinaemia and chronic giardiasis. The first was isolated before any treatment had been given and the second after three unsuccessful courses of metronidazole. We have characterised the isolates with respect to susceptibility to metronidazole and quinacrine, DNA fingerprinting, profiles of iodinated surface proteins, ${ }^{35} \mathrm{~S}$-methionine protein profiles, and isoenzyme patterns. The use of these markers for distinguishing between isolates should allow us to explore the relations between strain type, drug resistance, and treatment failure and may ultimately contribute to our understanding of the pathophysiological mechanisms involved in chronic giardiasis.

\section{Methods}

AXENISATION AND CULTURE OF GIARDIA ISOLATES A 42 year old heterosexual man presented with a two year history of chronic diarrhoea. Faecal microscopy revealed Giardia lamblia cysts. Mean stool weight was increased at $500 \mathrm{~g}$ in 24 hours but faecal fat excretion was within normal limits at $16.6 \mathrm{mmol} / 24 \mathrm{~h}$ (normal range $6-18 \mathrm{mmol}$ / $24 \mathrm{~h}$ ). Barium contrast radiology and endoscopy of the small and large intestine showed generalised lymphoid nodular hyperplasia that was confirmed histologically. The most significant abnormal finding was panhypo- $\gamma$ globulinaemia. All serum immunoglobulin concentrations were low (IgA not detectable, IgG $5 \cdot 1$ (normal range 7-18) g/l, IgM 0.16 (normal range 0.4-2.5) g/l. ie.um anti-Giardia antibodies were measured by enzyme linked immunosorbent assay (ELISA). Specific IgG (titre 1:400) was lower than would be expected in a patient with continuing infection $^{12}$ and specific IgM and IgA antibodies were not detected. Similarly, we were unable to detect specific secretory IgA in duodenal fluid. On the basis of these findings he was presumed to have chronic giardiasis, hypo- $\gamma$ globulinaemia of the common variable type, and lymphoid nodular hyperplasia.

He was treated with $2 \mathrm{~g}$ metronidazole daily for three days with initial reduction in stool frequency and Giardia cyst excretion, although bowel habit never returned to normal. He received two further courses of $2 \mathrm{~g}$ metronidazole daily for three days on two consecutive weeks with initial improvement in stool frequency and reduction in cyst numbers. The diarrhoea returned, however, and he continued to excrete Giardia cysts. Duodenal aspirate confirmed the presence of Giardia trophozoites in the small bowel. 
Duodenal aspirates were taken at the initial clinical investigation and again three months later after three courses of metronidazole. Aspirates were transported to the laboratory on ice and the trophozoites counted by direct microscopy with a haemocytometer. Aliquots of the aspirates were centrifuged at $4^{\circ} \mathrm{C}$ for 10 minutes at $1000 \mathrm{~g}$ and the pelleted trophozoites washed once in filter sterilised, modified Diamond's TYI-S medium ${ }^{1314}$ without bile, containing $10 \%$ heat inactivated newborn calf serum with penicillin $(100 \mathrm{IU} / \mathrm{ml})$, streptomycin $(200 \mathrm{u} / \mathrm{ml})$, gentamicin $(50 \mu \mathrm{g} / \mathrm{ml})$, and amphotericin B $(0.8 \mu \mathrm{g} / \mathrm{ml})$. Fresh culture medium in $16 \mathrm{ml}$ borosilicate glass screw top tubes was then inoculated with $10^{6}$ washed trophozoites and incubated at $37^{\circ} \mathrm{C}$. Trophozoites attached after several hours and the medium was changed. Growth was monitored microscopically and the medium changed every 24-48 hours. Cultures were subcultured after semiconfluent growth was seen and the antibiotics withdrawn after one to two weeks. No signs of bacterial or yeast growth were seen after this time and axenic growth was established.

\section{DRUG SENSITIVITY ASSAY}

Antigiardial activity of metronidazole and mepacrine were determined over the concentration range $0 \cdot 01-1000 \mu \mathrm{mol} / \mathrm{l}$ as described previously. ${ }^{15}$ Briefly, cultures were initiated with $2 \times 10^{5}$ trophozoites in $0.5 \mathrm{ml}$ of medium from late $\log$ phase growth and incubated for 24 hours. Duplicate tubes were set up and growth assessed by counting trophozoite numbers and comparing this with that of drug free controls. Inhibition of growth was expressed as minimal inhibitory concentration (MIC), the lowest drug concentration that completely inhibited growth, and the dose that inhibited growth by $50 \%$ $\left(\mathrm{ED}_{50}\right) \cdot{ }^{15}$

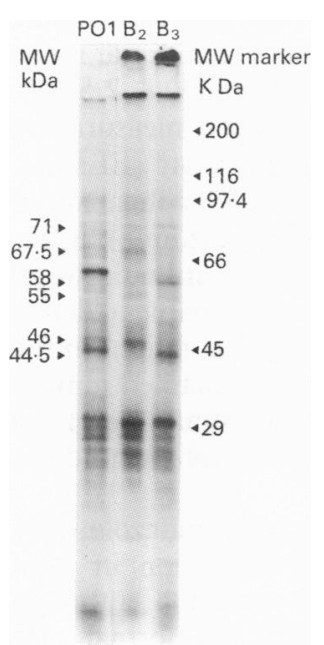

Figure 1: Fluorograph of and $B 3$ laballed with ${ }^{33} \mathrm{~S}$ methionine after electrophoresis in $10 \%$ polyacrylamide-SDS gel. polyacrylamide-SDS gel. are indicated $(\rightarrow)$ and relative molecular weights calculated from size markers.

\section{METABOLIC RADIOLABELLING WITH}

${ }^{35}$ S-METHIONINE

Trophozoites $\left(2 \times 10^{6}\right)$ harvested during log growth were resuspended in $0.5 \mathrm{ml}$ Diamond's TYI-S medium without serum or bile and incubated for four hours at $37^{\circ} \mathrm{C}$ with $20 \mu \mathrm{Ci}^{35} \mathrm{~S}$ methionine (Amersham International PLC, UK). After radiolabelling, trophozoites were washed twice with phosphate buffered saline (PBS) containing $0.1 \mathrm{mmol} / 1$ methionine, pelleted, and resuspended in sodium dodecyl sulphate (SDS) sample buffer for electrophoresis on $10 \%$ SDS-polyacrylamide gels. ${ }^{16}$ After electrophoresis at $200 \mathrm{~V}$ for four hours, the gel was treated with Amplify (Amersham International PLC), dried, and visualised by fluorography for 10 days at $-70^{\circ} \mathrm{C}$.

Sensitivities of Giardia isolates to metronidazole and mepacrine $(\mu \mathrm{mol} / \mathrm{l})$

\begin{tabular}{llllll}
\hline & \multicolumn{2}{l}{ Metronidazole } & & \multicolumn{2}{c}{ Mepacrine } \\
\cline { 2 - 3 } \cline { 6 - 7 } Isolate & $E D_{50}$ & $M I C$ & & $E D_{50}$ & $M I C$ \\
\hline PO1 & 0.56 & 10.0 & & 10.0 & 100 \\
B2 & 0.03 & 0.1 & & 0.13 & 2.7 \\
B3 & 0.58 & 4.3 & & 1.8 & 12 \\
\hline
\end{tabular}

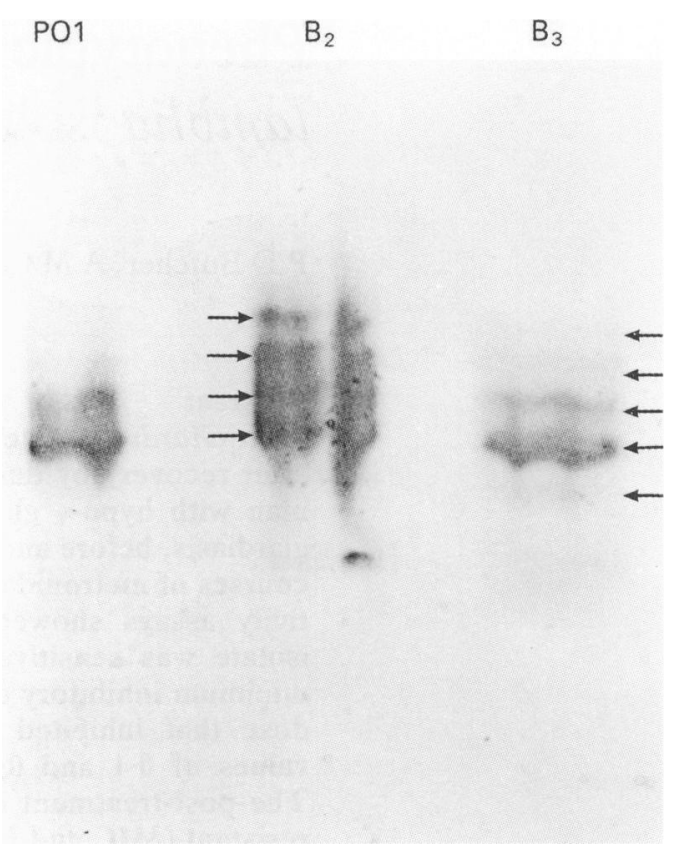

Figure 2: Isoenzyme patterns of malic enzyme analysed by isoelectric focusing of lysates from $\mathrm{G}$ lamblia strains $P O 1, B 2$, and B3. Arrows indicate individual bands, four in B2 and five in $B 3$.

\section{ISOENZYME ANALYSIS}

Trophozoites $\left(1 \times 10^{7}\right)$ from log phase cultures were harvested, washed three times in PBS, and lysed with $2 \%$ Triton X-100. Lysates were centrifuged at $10000 \mathrm{~g}$ for five minutes and separated by electrophoresis on flat bed $1 \%$ isoelectric focusing agarose (Pharmacia) at $20 \mathrm{~mA}$ and 1000 $\mathrm{V}$ for 20 minutes. Replica gels were stained for glucose-6-phosphate dehydrogenase (G6PDH; E.C.1.1.1.49), hexokinase (Hex; E.C.2.7.1.1), and malic enzyme (ME; E.C.1.1.1.40) by standard methods. ${ }^{17}$

RADIOIODINATION OF SURFACE PROTEINS

Surface radioiodination of $2 \times 10^{7}$ washed trophozoites from log growth was performed in plastic tubes coated with $100 \mu \mathrm{g}$ iodogen (Pierce Chemicals Ltd) in $100 \mu \mathrm{l}$ PBS pH 7 by incubation at $37^{\circ} \mathrm{C}$ for 10 minutes with $100 \mu \mathrm{Ci} \mathrm{Na}{ }^{125} \mathrm{I}$ (Amersham International PLC). Labelled trophozoites were washed three times in PBS containing $10 \mathrm{mmol} / \mathrm{l}$ glucose, $10 \mathrm{mmol} / 1$ dithiothreitol (DTT), and $10 \mathrm{mmol} / \mathrm{l}$ sodium iodide. Pelleted trophozoites were resuspended in 100 $\mu l$ lysis buffer $(10 \mathrm{mmol} / 1$ Tris-HCL $\mathrm{pH} 7 \cdot 4$, $1 \mathrm{mmol} / \mathrm{l} \mathrm{MgCl}, 0.25 \mathrm{mmol} / \mathrm{l} \mathrm{DTT}, 0.25 \mathrm{mmol} /$ 1 phenylmethylsulphonylfluoride, $0.5 \%$ Triton $\mathrm{X}-100$ ) and vortexed every five minutes for one hour at $4^{\circ} \mathrm{C}$ to extract surface membrane proteins. ${ }^{18}$ Detergent extracted proteins were centrifuged at $10000 \mathrm{~g}$ for 10 minutes, solubilised in equal volumes of sample buffer, and separated by electrophoresis on $10 \%$ SDS-polyarcylamide gels. Radioiodinated proteins were visualised by autoradiography at $-70^{\circ} \mathrm{C}$.

\section{DNA FINGERPRINTING WITH A M-13}

BACTERIOPHAGE PROBE

Total DNA was extracted from $10^{8}$ washed trophozoites by lysis in 1\% SDS in TEN buffer 


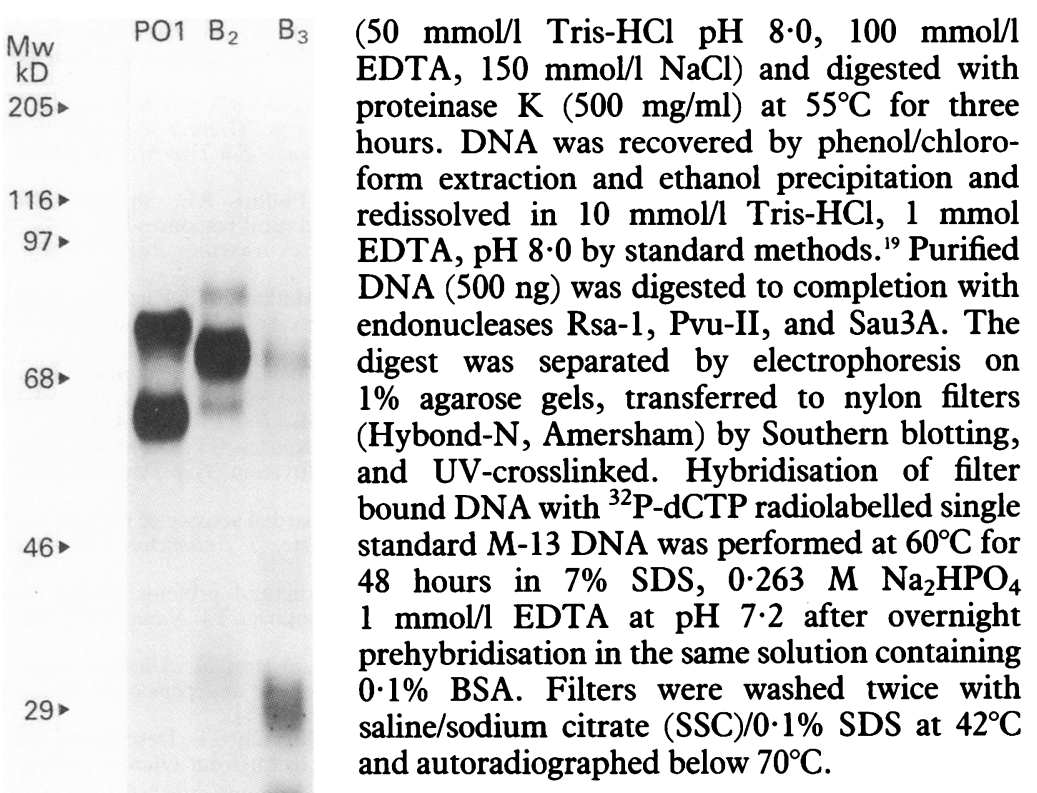

\section{Results}

20.1.

Figure 3: Autoradiograph of SDS-PAGE analysis of the surface membrane proteins after ${ }^{125}$ I labelling of trophozoites of $\mathrm{G}$ lamblia strains PO1, B2, and B3.

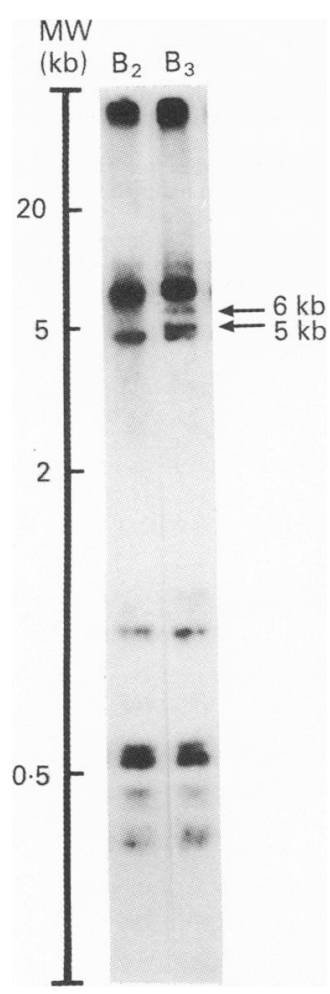

Figure 4: Autoradiograph showing DNA fingerprint analysis of Sau $3 A$ cut genomic DNA from $\mathrm{G}$ lamblia strains $B 2$ and $B 3$ with the bacteriophage $\mathrm{M} 13$ gene III region tandem repeat sequence as a multilocus probe. Arrows denote bands at 5 and $6 \mathrm{~Kb}$ present in strain $B 3$ but not in strain B2.
CULTURE AND DRUG SENSITIVITIES

Two Giardia isolates from duodenal aspirates were established in axenic culture: the first (B2) was obtained before treatment and the second (B3) after three unsuccessful treatments with metronidazole. Sensitivity to metronidazole and mepacrine was measured in vitro for both isolates and the laboratory strain Portland 1 (PO1). The results were expressed as $\mathrm{ED}_{50}$ and MIC (Table). Sensitivities to metronidazole and isolate than in the $\mathrm{B} 2$ isolate, but intermediate between $\mathrm{B} 2$ and a standard laboratory isolate, PO1. The B3 isolate was $>20$-fold more resistant to metronidazole than $\mathrm{B} 2$ with $\mathrm{ED}_{50}$ and $>40$ fold with MIC as the index.

\section{PHENOTYPIC AND GENOTYPIC MARKERS}

\section{Radiolabelling with ${ }^{35} S$-methionine}

Metabolic radiolabelling of trophozoites with ${ }^{35} \mathrm{~S}$-methionine and analysis of the labelled protein profile by SDS-PAGE revealed qualitative and quantitative differences between the isolates (Fig 1); B2 showed unique proteins of $67 \cdot 5,55$ and $46 \mathrm{kDa}$ molecular weight, whereas B3 had major proteins of $44 \cdot 5,58$, and $71 \mathrm{kDa}$. Many common bands were seen.

\section{Isoenzymes}

Analysis of the isoelectrophoretic mobility of specific isoenzymes of $\mathrm{B} 2, \mathrm{~B} 3$, and $\mathrm{PO} 1$ revealed similar patterns for the enzymes G6PDH and however found in malic enzyme pattern (Fig 2). B3 showed 5 bands whereas B2 and PO1 showed the same pattern of 4 bands.

\section{Radiolabelling of surface protein}

Surface proteins of the Giardia isolates were analysed by SDS-PAGE and autoradiography after surface radiolabelling with ${ }^{125} \mathrm{I}$. Incorporamepacrine were substantially lower in the B3 hexokinase (data not shown). Differences were tion of ${ }^{125} \mathrm{I}$ into the detergent soluble membrane fraction ranged between $2 \cdot 0-11 \cdot 0 \times 10^{5} \mathrm{cpm} / 10^{6}$ trophozoites. Figure 3 shows the differences in the surface labelled proteins of the isolates and $\mathrm{PO}$. Isolate $\mathrm{B} 2$ had a major protein of $70 \mathrm{kDa}$ with minor components at $82,58,31$, and 22 $\mathrm{kDa}$. Isolate $\mathrm{B} 3 \mathrm{had}$ the $70 \mathrm{kDa}$ protein as a minor band with a major band at $24 \mathrm{kDa}$ and a third broad band at $28 \mathrm{kDa}$. Variation in surface proteins between the isolates was thus clearly shown; five other laboratory strains showed a pattern similar to PO1 (data not shown).

\section{DNA fingerprinting with an M-13 bacteriophage probe}

M-13 hybridisation bacteriophage with all three restriction endonucleases resulted in visualisation of $10-15$ bands per isolate ranging in size from 0.5 to $20 \mathrm{~kb}$. Several bands were common to both isolates but, there were clear differences between B2 and B3. The Sau 3A cut revealed the presence of two extra bands of around 5 and $6 \mathrm{~kb}$ in B3 that were absent in B2. There were also minor differences with the other two cuts (Fig 4).

\section{Discussion}

During the past 10 years it has been possible to cultivate Giardia lamblia in vitro and methods to differentiate Giardia isolates by isoenzyme profiles, ${ }^{2021}$ surface proteins, ${ }^{22-25}$ and DNA restriction fraction length polymorphism (RFLP) and DNA fingerprinting ${ }^{26-28}$ have been developed. With these methods we have characterised two Giardia isolates obtained from the same patient before and after failure to eradicate the parasite by three courses of metronidazole. The pretreatment isolate was 20 times more sensitive to metronidazole than the post-treatment isolate. Differences were also found in the ${ }^{125}$ I surface protein profiles, the metabolic labelling pattern with ${ }^{35} \mathrm{~S}$-methionine, malic enzyme isoenzyme patterns, and by DNA fingerprinting. The phenotypic and genotypic non-identity of the two isolates suggest that they are in fact two different strains.

Adaptation by Giardia to metronidazole can be induced in vitro by exposure to sublethal doses of the drug over a period of 66 weeks; this is reversible after drug withdrawal by 22 weeks. $^{10}$ The time scale over which adaptation occurred in vitro is very different from the situation of our patient in vivo, namely three periods of three days of exposure to high concentrations of drug.

Giardia lamblia isolates can change their antigenic profile in vitro and in vivo. ${ }^{2224-25}$ This could explain the changes seen in the ${ }^{125}$ I surface protein profiles in our isolates but cannot account for the other phenotypic and genotypic differences. It seems highly unlikely that only spontaneous phenotypic variation within the same isolate could have occurred when so many other differences have been found.

A critical question is whether the first (B2) and second (B3) were both present at the start of the infection. Axenization of Giardia isolates is itself a selection process, more robust strains being presumably more likely to survive the procedure. Thus even if exhaustive cloning of the 
initial isolate B2 failed to show the presence of B3, this would not exclude the possibility that B3 could have contributed to the primary infection; the assumption would be that the more abundant or more rapid growing B2 would have survived preferentially in vitro. Alternatively, but perhaps less likely, is that immediate reinfection with isolate B3 strain may have occurred either by intrafamilial contact or zoonotic infection from pets. Cyst excretion continued, however, throughout the treatment period, and screening of family members and a pet dog failed to identify other Giardia infections, making this explanation unlikely.

Thus our findings suggest that the mechanism of treatment failure in this case was due to selection of a Giardia strain with increased resistance to metronidazole from an existing heterogenous population of Giardia clones with variable sensitivities in the initial infection.

MJGF is a Wellcome Trust senior lecturer. We are indebted to the Wellcome Trust for financial support. AMC is supported by a grant from CONACYT, Mexico.

1 Kavousi S. Giardiasis in infancy and childhood: a prospective study of 160 cases with comparison of quinecrine (Atabrine) and metronidazole (Flagyl). Am $\mathcal{F}$ Trop Med Hyg 1979; 28: 19-23.

2 Smith PD, Gillin FD, Spira WM, Nash TE. Chronic giardiasis: studies on drug sensitivities, toxin production and host immune responses. Gastroenterology 1982; 83: 797803.

3 Bassily S, Farid Z, El-Masry NA, Mikhail ME. Treatment of intestinal $E$ histolytica and $G$ lamblia with metronidazole, tinidazole and ornidazole: a comparative study. $\mathcal{F}$ Trop Med Hyg 1987; 90: 9-12.

4 Gascon J, Moreno A, Valls ME, Miro JM, Corachan M. Failure of mebendazole treatment in Giardia lamblia Failure of mebendazole treatment in Giardia

5 Taylor GD, Wenman WM, Tyrrell DL J. Combined metronidazole and quinacrine hydrochloride therapy for chronic
nator nidazole and quinacrine hydrochloride therapy

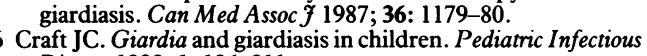
Disease 1982; 1: 196-211.

7 Davidson RA. Issues in clinical parasitology: the treatment of giardiasis. Am $\mathcal{F}$ Gastroenterol 1984; 79: 256-61

8 Lerman SJ, Walker RA. Treatment of giardiasis: literature review and recommendations. Clin Paediatr 1982; 21 : 409 14.
9 Boreham PFL, Phillips RE, Sheperd RW. The sensitivity of Giardia intestinalis to drugs in vitro. $\mathcal{f}$ Antimicrob Chemother 1984; 14: 449-61.

10 Boreham PFL, Phillips RE, Sheperd RW. Altered uptake of metronidazole in vitro by stocks of Giardia intestinalis with different drug sensitivities. Trans $R$ Soc Trop Med Hyg 1988; 82: $104-6$.

11 McIntyre P, Boreham PFL, Phillips RE, Sheperd RW Chemotherapy in giardiasis: clinical responses and in vitro drug sensitivity of human isolates in axenic culture. $\mathcal{F}$ Pediat 1986; 108: 1005-10.

12 Goka AKJ, Rolston DDK, Mathan VI, Farthing MJG. Diagnosis of giardiasis by specific IgM antibody ELISA Lancet 1986; ii: $184-6$.

13 Diamond LS, Harlow DR, Cunnick CC. A new medium for the axenic cultivation of Entamoeba histolytica and other Entameba. Trans R Soc Trop Med Hyg 1978; 72: 431-2.

14 Farthing MJG, Pereira MEA, Keusch GT. Giardia lamblia: evaluation of roller bottle cultivation. Exp Parasitol 1982; 54: 410-5.

15 Farthing MJG, Inge PM. Antigiardial activity of the bile saltlike antibiotic sodium fusidate. 7 Antimicrob Chemother like antibiotic sodiu

16 Laemmli UK. Cleavage of structural proteins during the assembly of the head of bacteriophage T4. Nature $1970 ; 227$ : $680-5$.

17 Richardson BJ, Baverstock PR, Adams M. Allozyme electrophoresis: a handbook for systematic and population studies. Sydney: Academic Press, 1986.

18 Farthing MJG, Pereira MEA, Keusch GT. Description and characterisation of a surface lectin from Giardia lamblia. Infect Immun 1986; 51: 661-7.

19 Maniatis T, Fritsch EF, Sambrook J. In: Molecular cloning. a laboratory manual. New York: Cold Spring Harbor Laboratory, 1982.

20 Andrews RH, Adams M, Boreham PFL, Mayrhofer G Meloni BP. Giardia intestinalis: electrophoretic evidence for Meloni BP. Giardia intestinalis: electrophoretic evide

21 Meloni BP, Lymbery AJ, Thompson RCA. Isoenzyme electrophoresis of 30 isolates of Giardia from humans and felines. Am F Trop Med Hyg 1988; 38: 65-73.

22 Aggarwal A, Nash TE. Antigenic variation of Giardia lamblia in vivo. Infect Immun 1988; 56: 1420-3.

23 Nash TE, Keister DB. Differences in excretory-secretory products and surface antigens among 19 isolates of Giardia. I Infect Dis 1985; 152: 1166-71

24 Nash TE, Aggarwal A, Adam RD, Conrad JT, Merritt JW Antigenic variation in Giardia lamblia. $\mathcal{F}$ Immunol 1988; 141 636-41.

25 Adam RD, Aggarwal A, Lal AA, de la Cruz VF, McCutchan $T$, Nash TE. Antigenic variation of a cystein rich protein in T, Nash TE. Antigenic variation of a cystein rich

26 Nach TE, McCutchan T, Keister D, Dame JB, Conrad JD, Gillin FD. Restriction endonuclease analysis of DNA from 15 Giardia isolates from humans and animals. F Infect Dis 1985; 152: 64-73.

27 Butcher PD, Farthing MJG. DNA probes for the faecal diagnosis of Giardia lamblia infections in man. Biochem Soc Trans 1988; 17: 363-4.

28 Upcroft P, Mitchell R, Borenham PFL. DNA fingerprinting of the intestinal parasite Giardia duodenalis with the M13 phage genome. Int $\mathcal{F}$ Parasitol 1990; 20: 419-23. 